\title{
Biosynthesis of dermatan sulphate
}

\author{
Assay and properties of the uronosyl C-5 epimerase
}

\author{
Anders MALMSTRÖM and Lena ÅBERG \\ Department of Physiological Chemistry 2, University of Lund, Box 750, S-220 07 Lund, Sweden
}

(Received 24 August 1981/Accepted 23 October 1981)

During biosynthesis of dermatan sulphate D-glucuronate (GlcA) residues are converted to $\mathrm{L}$-iduronate (IdoA) residues via the reaction

$$
-\mathrm{GlcA}-\frac{\stackrel{H}{H}_{\mathrm{H}}}{\longrightarrow}-\mathrm{IdoA}-\text {. }
$$

The reaction occurs on the polymer level and is catalysed by a C-5 uronosyl epimerase. The reversible release of the $\mathrm{C}-5$ hydrogen was utilized as a measure of the enzyme activity with $5-{ }^{3} \mathrm{H}$-labelled chondroitin as a substrate. ${ }^{3} \mathrm{H}$ released during incubation was distilled and quantified by liquid-scintillation counting. The epimerase has a low $\mathrm{pH}$ optimum (5.6) and requires divalent cations, $\mathrm{Mn}^{2+}$ being the most efficient for activity. The $K_{\mathrm{m}}$ for chondroitin is $1.2 \times 10^{-4} \mathrm{M}$. The epimerase is largely associated with the microsomal fractions (90\%). Two-thirds of the activity can be solubilized by detergents. Microsomes from cultured fibroblasts contain two different uronosyl epimerases, one for the biosynthesis of heparan sulphate and one for that of dermatan sulphate. The two epimerases have different cofactor and $\mathrm{pH}$ requirements.

Both heparin/heparan sulphate and dermatan sulphate contain the rather unusual sugar residue L-iduronate. The formation of this sugar occurs by C-5 epimerization of D-glucuronate residues in polysaccharide precursors (Höök et al., 1974; Malmström et al., 1975). The process is enhanced by concomitant sulphation of the polysaccharide precursors. The initial step in the epimerization process is an abstraction of the C-5 hydrogen of the target uronosyl residues (Jacobsson et al., 1979; Malmström, 1981). This property has been utilized to construct an assay for the heparosan epimerase with a ${ }^{5}{ }^{3} \mathrm{H}$-labelled polymer as a substrate. Enzymatic activity is measured by the release of ${ }^{3} \mathrm{H}$. The same approach has now been used to assay the dermatan sulphate epimerase. Properties of the epimerase are described, and evidence is presented to show that the two epimerases are different.

\section{Experimental}

\section{Materials}

Chondroitin 4-sulphate from beef nasal septum was prepared as described (Fransson \& Malm-

Abbreviations used: IdoA, iduronic acid; Mes, 4morpholine-ethanesulphonic acid; Hepes, 4-(2-hydroxyethyl)-1-piperazine-ethanesulphonic acid. ström, 1971). Dermatan sulphate was a gift from Dr. L. Rodén, Birmingham, AL, U.S.A., and it was isolated from heparan side fractions by alkaline copper precipitation (Lindahl et al., 1965). The remaining heparan sulphate was removed after treatment with $\mathrm{HNO}_{2}$ at $\mathrm{pH} 1.5$ (Shively \& Conrad, 1976) and chromatography on a column of Sephadex G-50. In order to decrease the amount of glucuronate in dermatan sulphate, $100 \mathrm{mg}$ of dermatan sulphate was dissolved in $5 \mathrm{ml}$ of $0.1 \mathrm{M}$ -

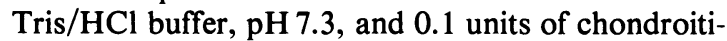
nase AC-II were added three times over a period of $16 \mathrm{~h}$. The digest was subsequently chromatographed on a column $(2.2 \mathrm{~cm} \times 145 \mathrm{~cm})$ of Sephadex G-100, which was equilibrated in $0.2 \mathrm{M}$-acetic acid/pyridine buffer, pH5.0. The major part (90\%) of the remaining polysaccharide that chromatographed in the void volume was pooled. Chondroitin sulphate and chondroitinase AC-treated dermatan sulphate was desulphated three times with acid methanol as described by Kantor \& Schubert (1957). After this treatment the galactosaminoglycans contained less than $0.1 \%$ of sulphate. As this procedure partly depolymerizes the polysaccharides the desulphated de-esterified product was chromatographed on a Sephadex G-100 column. Material containing uronic acid and eluting between $K_{\text {av. }} 0.15$ and 0.35 was pooled. 
Heparin (155 units/mg) was purchased from Inolex Pharmaceutical Division, Park Forest South, IL, U.S.A. Dextran sulphate $\left(M_{\mathrm{r}} 60000\right)$ and Sephadex G-100 were obtained from Pharmacia. Ion-exchange resin (DE-52) was a product of Whatman. Materials for cell culture work were purchased from Flow Laboratories. $\left[5-{ }^{3} \mathrm{H}\right] \mathrm{Heparan}$ (specific radioactivity $1245 \mathrm{~d} . \mathrm{p.m} . / \mu \mathrm{g}$ of uronic acid) was a gift from Dr. L. Rodén and was prepared enzymically (Prihar et al., 1980) by incubating desulphated and re- $N$-sulphated heparin with partially purified epimerase and $\left.{ }^{3} \mathrm{H}_{2} \mathrm{O} .{ }^{[} 5^{3} \mathrm{H}\right]$ Chondroitin was prepared from epiphyses of 12-day-old chicken, which were incubated with $1 \mathrm{mCi}$ of $\left[5-{ }^{3} \mathrm{H}\right]$ glucose in $5 \mathrm{ml}$ of Krebs-Ringer solution for $6 \mathrm{~h}$. The epiphyses were digested with papain and the chondroitin sulphate was recovered by cetylpyridinium chloride precipitation (Fransson \& Malmström, 1971). The $\left[5^{-}{ }^{3} \mathrm{H}\right]$ chondroitin sulphate was desulphated as described by Kantor \& Schubert (1957). The final product $\left[5-{ }^{3} \mathrm{H}\right]$ chondroitin had a specific activity of 18200 d.p.m./ $\mu \mathrm{g}$ of uronic acid. Chondroitinase $\mathrm{ABC}$ digestion followed by distillation showed that $40 \%$ of the radioactivity was located at C-5 of the uronosyl residues (chondroitinase ABC acts as an 'eliminase' and digestion of a substrate containing $5-{ }^{3} \mathrm{H}$-labelled glucuronosyl or iduronosyl residues liberates ${ }^{3} \mathrm{H}$ and creates 4,5unsaturated glycuronosyl residues.) Adenosine 3'phosphate $5^{\prime}$-phosphosulphate was prepared by using enzymes from a rat liver high speed supernatant as described by Jacobsson et al. (1979).

Epimerase enzyme was prepared from cultured human skin fibroblasts. The cells were cultured as described earlier (Malmström et al., 1975). Cells in monolayer between 5 and 12 passages were rinsed twice with phosphate-buffered saline $(137 \mathrm{~mm}-\mathrm{NaCl} /$ $3 \mathrm{~mm}-\mathrm{KCl} / 8 \mathrm{~mm}-\mathrm{Na}_{2} \mathrm{HPO}_{4} / 1 \mathrm{~mm}-\mathrm{KH}_{2} \mathrm{PO}_{4}, \mathrm{pH} 7.4$ ) detached by shaking with $0.5 \mathrm{~mm}$-disodium EDTA in phosphate-buffered saline and collected by centrifugation at $400 \mathrm{~g}$ for $2 \mathrm{~min}$. The cells were rinsed with phosphate-buffered saline and then dispersed in $10 \mathrm{vol}$. of $0.25 \mathrm{M}$-sucrose, $\mathrm{pH} 7.4$, and homogenized with ten strokes at $2000 \mathrm{rev} . / \mathrm{min}$ in a Potter-Elvehjem homogenizer. The homogenate was centrifuged at $600 \mathrm{~g}$ for $10 \mathrm{~min}$. The supernatant was subsequently centrifuged at $10000 \mathrm{~g}$ for $20 \mathrm{~min}$. The $600 \mathrm{~g}$ pellet was rehomogenized and recentrifuged as above. This procedure was repeated four times. The $10000 \mathrm{~g}$ supernatants were combined and centrifuged at $105000 \mathrm{~g}$ for $1 \mathrm{~h}$. The $600 \mathrm{~g}$, the $10000 \mathrm{~g}$ and the $105000 \mathrm{~g}$ pellets were suspended by gentle homogenization in $0.05 \mathrm{M}$-Hepes, $\mathrm{pH} 6.5$, in a Potter-Elvehjem homogenizer and stored at $-60^{\circ} \mathrm{C}$. Solubilization of microsomal enzyme was carried out as described by Schwartz \& Rodén (1975). Briefly, microsomal preparations were sonicated in $0.1 \mathrm{M}$-Hepes, pH 6.2, containing 0.5\% Nonidet P-40.
After sonication solid $\mathrm{KCl}$ was added to a final concentration of $0.5 \mathrm{M}$ and the mixture was incubated for $30 \mathrm{~min}$. Finally the solubilized enzyme was separated from the remaining membranes by centrifugation at $105000 \mathrm{~g}$ for $1 \mathrm{~h}$.

\section{Enzyme assays}

The dermatan sulphate epimerase was assayed in a final volume of $100 \mu \mathrm{l}$ of $25 \mathrm{~mm}$-Mes, $\mathrm{pH} 5.6$, containing $10 \mathrm{mM}-\mathrm{MnCl}_{2}, 0.5 \%$ Nonidet NP 40 , 68000 d.p.m. (4 $\mu \mathrm{g}$ of uronic acid) of $\left[5-{ }^{3} \mathrm{H}\right]-$ chondroitin and $50-150 \mu \mathrm{g}$ of microsomal protein. In the standard procedure the samples were incubated for $4 \mathrm{~h}$ and then boiled for $3 \mathrm{~min}$. After addition of $200 \mu \mathrm{l}$ of water the samples were distilled (Jacobsson et al., 1979) and $200 \mu \mathrm{l}$ was counted in a Packard 2650 liquid-scintillation counter.

In order to study the $\mathrm{pH}$-dependence of the enzyme the reaction was carried out either in $25 \mathrm{~mm}$-sodium acetate (pH 4.5-5.6), $25 \mathrm{~mm}$-Mes (pH 5.3-6.5) or 25 mM-Hepes (pH 7.0-7.5).

Heparan sulphate epimerase was assayed in a final volume of $100 \mu \mathrm{l}$ of $50 \mathrm{~mm}$-Hepes, $\mathrm{pH} 7.4$, containing $50 \mathrm{~mm}-\mathrm{KCl}, 15 \mathrm{~mm}-\mathrm{EDTA}, 0.5 \%$ Nonidet NP 40, 29900 d.p.m. ( $24 \mu \mathrm{g}$ of uronic acid) of [5- $\left.{ }^{3} \mathrm{H}\right]$ heparin and $50-150 \mu \mathrm{g}$ of microsomal protein. The procedure was then as above.

\section{Analytical methods}

Protein was quantified by the method of Lowry et al. (1951). Before analysis, interfering salts were removed by trichloroacetic acid precipitation of the protein followed by resolubilizing it in alkali as described by Malmström (1981). Uronic acid was measured with the carbazole reaction (Bitter \& Muir, 1962). Chondroitinase-ABC digestions were carried out as described by Yamagata et al. (1968).

\section{Results}

Incubation of $\left[5-{ }^{3} \mathrm{H}\right]$ chondroitin with a particulate enzyme preparation from cultured fibroblasts resulted in a linear release of ${ }^{3} \mathrm{H}$ with time. The ${ }^{3} \mathrm{H}$ was recovered by distillation after it had equilibrated with the water of the incubation medium (Scheme 1). The pH optimum of the reaction was approx. 5.5. The same optimum was obtained both with sodium acetate and Mes buffers, although the enzyme was 1.6-fold more active in the latter buffer. The enzyme is, however, active over a $\mathrm{pH}$ range from 5 to 7 . The epimerase has an absolute requirement for divalent cations, $\mathrm{Mn}^{2+}$ being the most efficient (Fig. 1), while $\mathrm{Ca}^{2+}$ and $\mathrm{Mg}^{2+}$ are poorer activators. The optimal concentration of $\mathrm{Mn}^{2+}$ is $10 \mathrm{mM}$, but at higher concentrations there is inhibition. The enzyme is sensitive to ionic strength, as increasing concentrations of $\mathrm{KCl}$ or $\mathrm{NaCl}$ (Fig. 1) 


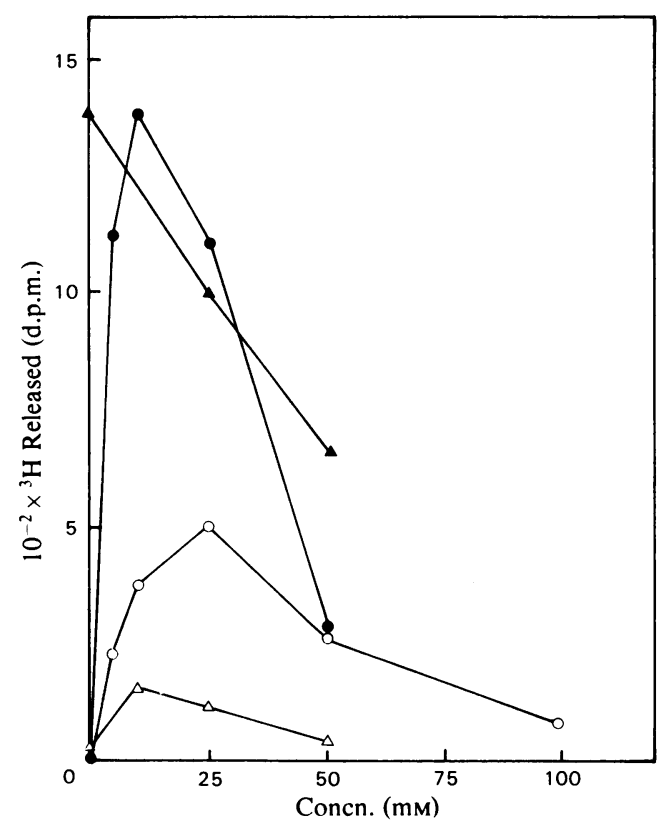

Fig. 1. Effect of different divalent cations and ionic strength on the epimerase activity

Microsomal enzyme preparations from fibroblasts were incubated with $\left[5-{ }^{3} \mathrm{H}\right]$ chondroitin in the presence of various concentrations of $\mathrm{Mg}^{2+}(\triangle), \mathrm{Ca}^{2+}$ $(\mathrm{O}), \mathrm{Mn}^{2+}(\mathrm{O})$ or $\mathrm{KCl}(\Delta)$ under otherwise standard incubation conditions. The experiment with $\mathrm{KCl}$ was performed with $10 \mathrm{~mm}-\mathrm{MnCl}_{2}$ in the incubation mixture.

in the presence of optimal divalent-ion concentrations decreased the activity. Detergents considerably enhanced the reaction rate and Nonidet at a concentration of $0.5 \%$ increased the activity 1.5 fold. The $K_{\mathrm{m}}$ for $\left[5^{-3} \mathrm{H}\right]$ chondroitin was $1.2 \times 10^{-4} \mathrm{M}$, expressed as molarity of glucuronate residues. The concentration of substrate used in the subsequent assays was, to economize on the substrate, $2.3 \times$ $10^{-4} \mathrm{M}$. Under these conditions the release of ${ }^{3} \mathrm{H}$ was linear with time for at least $8 \mathrm{~h}$ and linear with concentration of microsomal protein up to $250 \mu \mathrm{g}$.

In order to elucidate the substrate specificity of the epimerase various polysaccharides were added to the incubation mixture. Thus, if the added derivative is a substrate, a decrease of specific activity occurs which would result in a decrease in the release of ${ }^{3} \mathrm{H}$. As shown in Fig. 2, addition of chondroitin diminished the release of ${ }^{3} \mathrm{H}$, as did dermatan, which should be the product in the reaction. Sulphated polysaccharides were, however, much better inhibitors of ${ }^{3} \mathrm{H}$ release than were non-sulphated polysaccharides. Again, dermatan sulphate was more inhibitory than was chondroitin sulphate. Heparin was the best inhibitor. Dextran sulphate

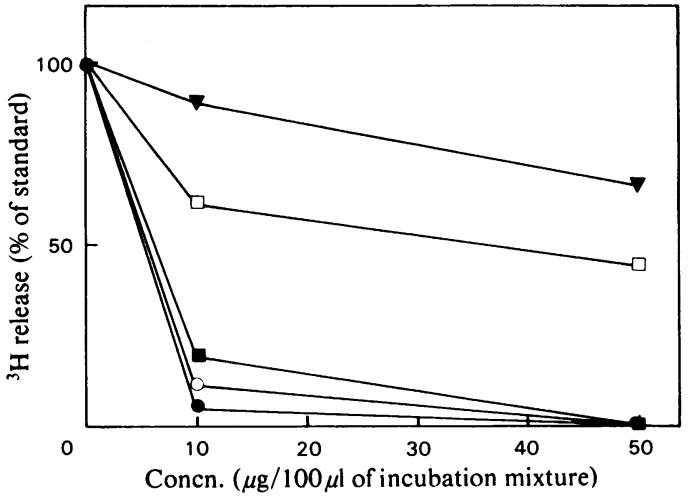

Fig. 2. Effect of various polysaccharides on the epimerase activity

Microsomal enzyme was incubated under standard conditions with different concentrations of chondroitin ( $\nabla)$, dermatan $(\square)$, chondroitin sulphate ( $\square$ ), dermatan sulphate $(O)$, or heparin $(O)$.

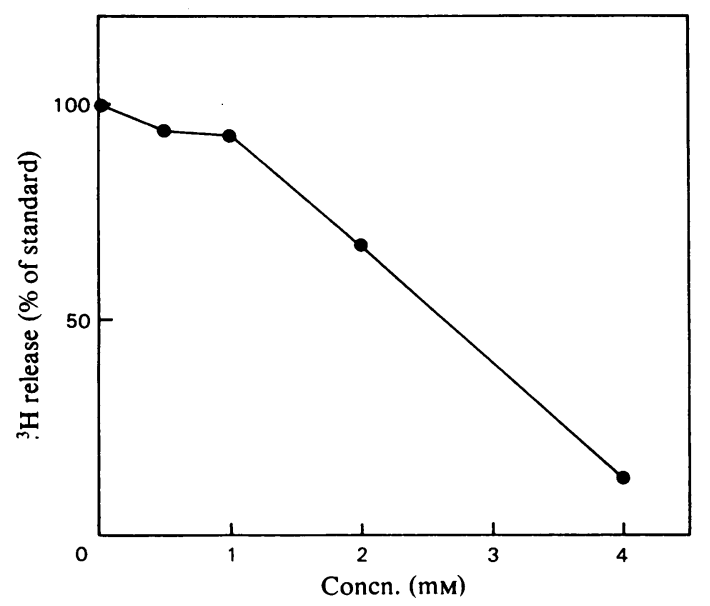

Fig. 3. Effect of adenosine 3'-phosphate 5'-phosphosulphate on epimerase activity

Microsomal enzyme was incubated under standard conditions with different concentrations of adenosine 3 '-phosphate 5 '-phosphosulphate.

(results not shown) was as inhibitory as chondroitin sulphate, which suggests that the inhibition of ${ }^{3} \mathrm{H}$ release was not only caused by substrate competition by the added polysaccharide. Adenosine 3'-phosphate $5^{\prime}$-phosphosulphate also inhibited the release of ${ }^{3} \mathrm{H}$ from $\left[5-{ }^{3} \mathrm{H}\right]$ chondroitin above a concentration of $1 \mathrm{~mm}$ (Fig. 3). No other experiments have yet been performed to elucidate the mechanism of the inhibition.

The distribution of the epimerase in different subcellular fractions was also investigated. Table 1 
Table 1. Distribution of epimerase activity in various subcellular fractions

Fibroblast were cultured, harvested, homogenized and fractionated as described in the Experimental section. The various fractions were assayed for epimerase activity and protein.

$\begin{array}{cccc}\text { Fraction } & \begin{array}{c}\text { Total protein } \\ (\mathrm{mg})\end{array} & \begin{array}{c}\text { Total activity } \\ (\%)\end{array} & \begin{array}{c}\text { Specific activity } \\ \text { (d.p.m. of }{ }^{3} \mathrm{H} \text { released } / \mathrm{h} \\ \text { per } \mathrm{mg} \text { of protein) }\end{array} \\ 600 \mathrm{~g} \text { pellet } & 29.8 & 4 & 130 \\ 10000 \mathrm{~g} \text { pellet } & 27.9 & 36 & 1340 \\ 105000 \mathrm{~g} \text { pellet } & 19.6 & 53 & 2860 \\ 105000 \mathrm{~g} \text { supernatant } & 52.5 & 8 & 150\end{array}$

shows that the enzyme is largely (more than 90\%) associated with the microsomal membranes. The highest specific activity was found in the $105000 \mathrm{~g}$ pellet. The distribution of the activity between the $10000 \mathrm{~g}$ pellet and $105000 \mathrm{~g}$ pellet fractions varies between preparations, but the highest specific activity was always obtained in the $105000 \mathrm{~g}$ fraction. The epimerase is firmly bound to the microsomes, as freezing followed by centrifugation released less than $20 \%$ of the enzyme activity. Sonication in detergent and subsequent addition of $\mathrm{KCl}$ to $0.5 \mathrm{M}$, however, solubilized $60 \%$ of the activity. The remainder was still found within the membranes.

As the dermatan sulphate epimerase is similar to the heparan sulphate epimerase, experiments were designed to investigate if the two enzymes were identical. Experiments were therefore carried out with a biosynthetically labelled heparin derivative and fibroblast microsomes at pH 7.4 with EDTA (optimal conditions for heparosan epimerase) as described by Malmström et al. (1980) and indeed heparan sulphate epimerase activity was noted (Fig. $4 a$ ). The reaction was linear for at least $2 \mathrm{~h}$. When $\left[5-{ }^{3} \mathrm{H}\right]$ chondroitin was incubated under the same conditions, no release of ${ }^{3} \mathrm{H}$ could be seen (Fig. $4 a$ ). The two substrates were also incubated under conditions optimal for the dermatan sulphate epimerase. As shown in Fig. 4(b) incubation with $\left[5-{ }^{3} \mathrm{H}\right]$ chondroitin resulted in a linear release of ${ }^{3} \mathrm{H}$ with time, whereas no activity with the ${ }^{3} \mathrm{H}$-labelled heparin derivative was detected (Fig. 4b). It can therefore be concluded that there are two different epimerases or active sites, one involved in dermatan sulphate biosynthesis and one in heparan sulphate biosynthesis.

\section{Discussion}

As shown earlier (Malmström, 1981) incubation of fibroblast microsomes with UDP $\left[5-{ }^{3} \mathrm{H}\right]$ glucuronate, UDP $\left[\mathrm{U}^{1{ }^{14} \mathrm{C}}\right.$ ]glucuronate, UDP- $N$-acetylgalactosamine and adenosine 3 '-phosphate 5'-phosphosulphate yields a dermatan sulphate polymer with $5-{ }^{3} \mathrm{H}$ - and $\mathrm{U}-{ }^{14} \mathrm{C}$-labelled glucuronate residues but only $\mathrm{U}-{ }^{14} \mathrm{C}$-labelled iduronate residues. Thus, release of ${ }^{3} \mathrm{H}$ appears to accompany the poly-

$$
\begin{aligned}
& \left(\left[5-{ }^{3} \mathrm{H}\right] \text { GlcA-GalNAc }\right)_{n} \stackrel{\text { Epimerase }}{\downarrow}\left(\text { IdoA/GlcA-GalNAc) }{ }_{n}\right. \\
& { }^{3} \mathrm{H} \rightarrow{ }^{3} \mathrm{H}_{2} \mathrm{O}
\end{aligned}
$$

Scheme 1. Epimerase action on $\left[5-{ }^{3} \mathrm{H}\right]$ chondroitin

mer-level C-5 epimerization of glucuronate to iduronate (see also Malmström et al., 1975). In the present study, incubation of an identical microsomal preparation with $\left[5-{ }^{3} \mathrm{H}\right]$ chondroitin as a substrate resulted in release of ${ }^{3} \mathrm{H}$ (Scheme 1). The ${ }^{3} \mathrm{H}$ which may be recovered from the medium as ${ }^{3} \mathrm{H}_{2} \mathrm{O}$ must be derived from the glucuronate residues of chondroitin, because exhaustive digestion of this substrate with chondroitinase-ABC liberated the same amounts of ${ }^{3} \mathrm{H}$. Hence, ${ }^{3} \mathrm{H}$ release may be used as a measure for epimerase activity.

Little is known about the regulation of the epimerase activity and also how the co-polymeric structure of the final product is attained. It has been shown earlier (Malmström et al., 1975) that epimerization and sulphation are tightly coupled during biosynthesis of dermatan sulphate. Incubation of UDP-glucuronic acid and UDP- $N$-acetylgalactosamine with microsomes yielded chondroitin with less than $10 \%$ of iduronic acid, while after addition of adenosine $3^{\prime}$-phosphate $5^{\prime}$-phosphosulphate synthesis of dermatan sulphate with approx. $60 \%$ iduronic acid was observed. At least three different explanations for the increase of iduronic acid residues by concomitant sulphation can be postulated, namely: (i) the optimal substrate for the epimerase is a sulphated structure, (ii) sulphation of the newly formed iduronosyl-containing disaccharide removes it from an equilibrium which favours glucuronosyl residues, or finally (iii) epimerase and sulphotransferase may be located together in the endoplasmic reticulum so that epimerization is directly following by sulphation.

The first possibility can be ruled out, as chondroitin is a much better substrate for the epimerase than is chondroitin sulphate (A. Malmström, unpublished work). The present results do not permit a distinction between the latter two possibilities. 


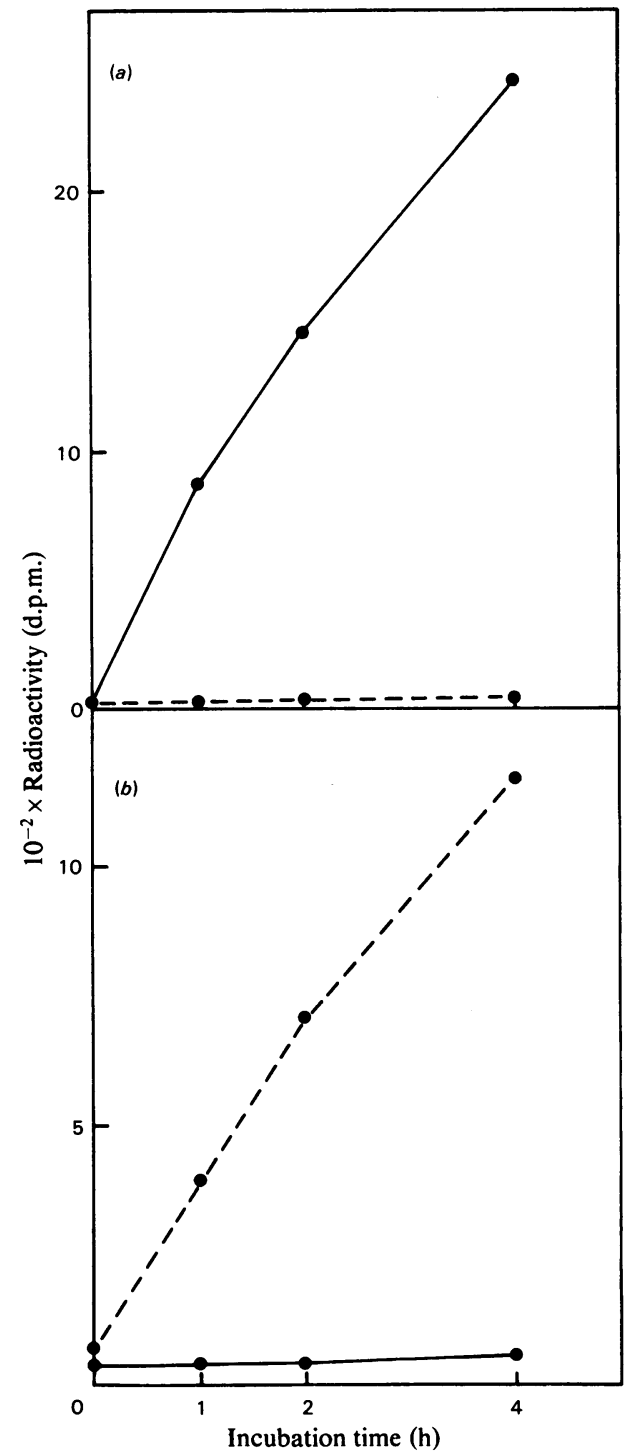

Fig. 4. Comparison of the activity of heparan sulphate and dermatan sulphate epimerases at (a) optimal conditions for the former enzyme and (b) optimal conditions for the latter enzyme

Microsomal enzyme preparations from fibroblasts were incubated with a $5-{ }^{3} \mathrm{H}$-labelled heparin derivative (-) or with $\left[5-{ }^{3} \mathrm{H} \mid\right.$ chondroitin (0---- a) as described in the Experimental section.

Sulphated polymers, however, efficiently inhibit the epimerase. This may indicate that sulphation is important as a regulator of the epimerase and that sulphation of the substrate prevents the action of the enzyme. Therefore adenosine 3 '-phosphate 5'-phosphosulphate may be an important regulator of epimerization, since in high concentrations it was inhibitory to the process. This effect is most likely not operative in vivo, as the concentration of adenosine 3'-phosphate 5'-phosphosulphate in the fibroblast is much lower than $2 \mathrm{mM}$ (B. Särnstrand, G. Ericksson, \& A. Malmström, unpublished work).

The dermatan sulphate and the heparan sulphate epimerases are most likely different enzymes, as $\mathrm{pH}$ optima, cation requirements and sensitivity to ionic strength are different. Furthermore, as shown in Fig. 4 , the dermatan sulphate epimerase is inactive when incubated under optimal conditions for the heparan sulphate epimerase, and vice versa. Further research involving purification and separation of the enzyme molecules are required to establish definitely this concept.

The work was supported by grants from the Medical Research Council $(5637,5670)$, Kocks Stiftelse, Alfred Österlunds Stiftelse, Gustaf V:s 80-ärsfond, the Medical Faculty of the University of Lund and Grant DE 2670 from the National Institutes of Health. Valuable suggestions by Drs. Lars-Áke Fransson, Ulf Lindahl and Lennart Rodén are acknowledged.

\section{References}

Bitter, T. \& Muir, H. M. (1962) Anal. Biochem. 4, 330-334

Fransson, L. Å. \& Malmström, A. (1971) Eur. J. Biochem. 18, 422-430

Höök, M., Lindahl, U., Bäckström, A. \& Fransson, L. Å. (1974) J. Biol. Chem. 249, 3908-3915

Jacobsson, I., Bäckström, G., Höök, M., Lindahl, U., Feingold, D. S., Malmström, A. \& Rodén, L. (1979) J. Biol. Chem. 254, 2975-2982

Kantor, T. G. \& Schubert, M. (1957) J. Am. Chem. Soc. 79, $152-154$

Lindahl, U., Cifonelli, J. A., Lindahl, B. \& Rodén, L. (1965) J. Biol. Chem. 240, 2817-2820

Lowry, O. H., Rosebrough, N. J., Farr, A. L. \& Randall, R. J. (1951) J. Biol. Chem. 193, 265-275

Malmström, A. (1981) Biochem. J. 198, 669-675

Malmström, A., Fransson, L.-Ȧ., Höök, M. \& Lindahl, U. (1975) J. Biol. Chem. 250, 3419-3425

Malmström, A., Rodén, L., Feingold, D. S., Jacobsson, I., Bäckström, G. \& Lindahl, U. (1980) J. Biol. Chem. 255, 3878-3883

Prihar, H., Campbell, P., Feingold, D. S., Jacobsson, I., Jensen, J. W., Lindahl, U. \& Rodén, L. (1980) Biochemistry 19, 495-500

Schwartz, N. B. \& Rodén, L. (1975) J. Biol. Chem. 250, 5200-5207

Shively, J. E. \& Conrad, H. E. (1976) Biochemistry 15, 3932-3942

Yamagata, T., Saito, H., Hubuchi, O. \& Suzuki, S. (1968) J. Biol. Chem. 243, 1523-1535 